\title{
Inflammatory bowel disease pathobiology: the role of the interferon signature
}

\author{
Nicolaos-Panagiotis Andreou, Evangelia Legaki, Maria Gazouli \\ Medical School, National and Kapodistrian University of Athens, Athens, Greece
}

\begin{abstract}
The pathogenesis of inflammatory bowel disease (IBD) is still unclear, but includes both inflammatory and autoimmune reactions. Current methodological approaches could better elucidate the cytokine pathways and the genetics involved in the etiopathogenesis of this disease. Interferons (IFNs) are cytokines that play a key role in autoimmune/inflammatory disorders because of their pro- and antiinflammatory properties as well as their immunoregulatory functions. An increased expression of IFN-regulated genes, widely known as an IFN signature, has been reported in blood and tissue from patients with autoimmune disorders. In this review, we present the function as well as the clinical and therapeutic potential of the IFN signature. Current data demonstrate that the IFN signature can be used as a biomarker that defines disease activity in autoimmune diseases, although this has not been thoroughly studied in IBD. Consequently, further investigation of the IFN signature in IBD would be essential for a better understanding of its actions.
\end{abstract}

Keywords Inflammatory bowel disease, interferon, interferon signature

Ann Gastroenterol 2020; 33 (2): 1-9

\section{Inflammatory bowel disease (IBD)}

IBD, including Crohn's disease (CD) and ulcerative colitis (UC), is a complicated, chronic, relapsing and heterogeneous disease induced by environmental, genomic, microbial, and immunological factors [1]. CD is a debilitating and incurable chronic idiopathic inflammatory disease of the intestine and is showing an increasing incidence in developing countries [2]. $\mathrm{CD}$ is characterized by ulceration and inflammation of the intestinal mucosa, which may affect the whole gastrointestinal tract, but mainly the distal small intestine. Typical characteristics of CD include discontinuous, transmural inflammation of the bowel wall, and the presence of granulomas, fistulas, strictures, and lymphoid aggregates [3]. UC is a chronic, idiopathic inflammatory disease that affects the colon. It is characterized by relapsing and remitting mucosal inflammation, starting in the rectum and extending to proximal segments of the colon.

Department of Basic Medical Sciences, Laboratory of Biology, Medical School, National and Kapodistrian University of Athens, Athens, Greece

\section{Conflict of Interest: None}

Correspondence to: Maria Gazouli, Department of Basic Medical Sciences, Laboratory of Biology, Medical School, National and Kapodistrian University of Athens, Athens, Greece, Michalakopoulou 176, 11527 Athens, Greece, e-mail: mgazouli@med.uoa.gr

Received 25 September 2019; accepted 17 December 2019; published online 12 February 2020

DOI: https://doi.org/10.20524/aog.2020.0457
UC is limited to the colon and only affects its innermost lining, while CD can develop anywhere in the gastrointestinal tract in all the layers of the bowel walls [4].

IBD therapy aims to induce and maintain clinical and endoscopic remission. Current treatments include aminosalicylate drugs and antibiotics for mild-to-moderate IBD, conventional anti-inflammatory agents (corticosteroids), immunosuppressants (thiopurines and methotrexate) and biologic therapy for moderate-to-severe disease. Recent data, however, suggest that the early initiation of more aggressive treatment, such as biologic therapy, can modify disease progression and may lead to less damage. Immunomodulatory drugsareoftenused in combination withbiologicsin IBD patients with severe disease for the maintenance of remission [5]. Apart from these well-studied treatments, systemic administration of type I interferon ([IFN], e.g., IFN- $\alpha$, IFN- $\beta$ ) in IBD patients has been evaluated for the suppression of disease burden, with controversial results. Immunoregulatory therapy with IFN type I can inhibit production of tumor necrosis factor (TNF) and IFN- $\gamma$, antagonize the IFN- $\gamma$ signaling pathway, and increase production of the anti-inflammatory cytokine interleukin (IL)-10 [6,7]. IFN- $\beta$ also has an immunoregulatory action by enhancing regulatory T-lymphocyte and natural killer-cell activity $[8,9]$.

\section{IBD and immunity}

IBD is characterized as an immune-mediated disease, although it still remains unknown whether this autoimmunity 
has a direct pathogenic effect in CD or in UC, despite the presence of autoantibodies that react to bacterial antigens [10].

\section{Innate immunity}

The role of innate immunity in the pathogenesis of IBD has been described since the discovery of mutations in the NOD2/CARD15 gene. The NOD2/CARD15 gene is an intracellular bacterial sensor, with reduced expression in the presence of the 3020insC mutation, leading to a vulnerability to bacterial infections in IBD [11]. NOD2/CARD15 mutations result in reduced $\alpha$-defensin expression. On the other hand, $\beta$-defensin levels are increased as a result of enteric inflammation; this is not the case for CD regarding HBD-2 and HBD-3 [12,13]. The combination of NOD2 mutations and the decreased defensin expression may lead to defective resistance against intestinal microorganisms and might result in inflammation of the mucosa [14].

Toll-like receptors (TLRs) also have an important role in innate immunity, through their ability to detect both normal and pathological microbes and to regulate the host's antimicrobial response [15]. Abnormal TLR expression or function has been implicated in the development or persistence of intestinal inflammation. TLR4 has been found to be upregulated in CD epithelial cells, while TLR3 is downregulated [16]. TLR4 and TLR9 polymorphisms have also been reported in IBD, but their functional significance is poorly understood $[17,18]$.

Because of the involvement of both NOD2 and TLRs in the recognition of and response to bacteria, they may have a reciprocal interaction that could be dysfunctional in IBD. Macrophages homozygous for NOD2 mutations in CD patients show defective production of IL-1 and IL- 8 when stimulated with muramyl dipeptide (MDP) or TNF- $\alpha$ [19]. In addition, peripheral blood mononuclear cells from double-mutant patients failed to interact with MDP and TLR ligands, leading to increased TNF- $\alpha$ and IL- $1 \beta$ production [20]. In this way, the generalized inability of the innate immune response to control via pattern recognition receptors may contribute to IBD, particularly to CD [14].

\section{Adaptive immunity}

IBD is characterized by increased production of systemic and mucosal antibodies and an altered amount of immunoglobulin classes and subclasses due to the chronic inflammation of the intestine [21-23]. Additionally, IgG1 antibodies against epithelial cells in the colon are highly produced in UC, but not in $\mathrm{CD}$, possibly demonstrating an autoimmune pathway in this case [24]. Lately, adaptive immunity in IBD has been focused on the subsets of T-helper (Th) cells (a lymphocyte subtype) and their soluble regulators, which are important elements of immune responses [25]. They are involved in the activation of other cells of the immune system and determine the specificity of antibodies secreted by B-cells [26]. Following proliferation, a Th cell is differentiated into Th1, Th2, or Th17 [27]. Th1 cells mediate the production of proinflammatory cytokines, such as IFN- $\gamma$, TNF- $\alpha$, and IL-12, whereas Th2 cells lead to the production of anti-inflammatory cytokines, including IL-4, IL-5, IL-6, and IL-10, which constitute the humoral immune response. There is an interaction between Th1 and Th2 lymphocytes. Th1 cytokines lead to the production of Th1 cells and inhibit Th2 cells. Conversely, Th2 cytokines lead to the production of Th2 cells and inhibit Th1 cells. In healthy individuals, there is an equilibrium between the quantities of Th1 and Th2 cells. The development of immune-mediated disorders such as CD is closely linked to a type 1 immune response causing chronic inflammation of the intestine. CD is characterized by the accumulation of Th1 cells and UC by the accumulation of Th 2 cells [28]. The most recent class of Th cells to be revealed is Th17 cells, differentiated in the presence of IL-6, IL-1 $\beta$, IL-21, and IL-23 [29], and may secrete IL-17A, IL-17F, IL -21, IL-22, IL-26, and chemokine CCL20 [30]. The inflamed mucosa of CD patients is characterized by a multi-complex communication network between cytokines, responsible for the changes that occur in immune level [31]. An example of this complicated, unstable process has been described in CD, with the transition from the Th1 response to a mixed phenotype of Th1/Th17 [32].

A great number of types of cytokine dysregulation have been described, in which proinflammatory and immunoregulatory molecules are included [25]. In CD patients, intestinal CD4+ T cells produce increased numbers of IFN- $\gamma$, while the transcription factor of Th1 cells, T-bet, is also overexpressed [33]. Mucosal macrophages also produce remarkable levels of IL-12 and IL-18 [34,35]. Regarding UC, different immunological abnormalities have been observed, where natural killer T (NKT) cells produce large amounts of IL-13, and T cells of mucosa produce more IL-15, proliferate less and die more than healthy cells [36].

\section{Genetics}

Genome-wide association studies (GWAS) have been crucial in the recognition of over 230 disease loci linked to IBD [37]. The most strongly and consistently implicated loci are associated with intracellular bacteria killing, innate (CARD15/ NOD2, IRGM, IL-23R, LRRK2, and ATG16L1) and adaptive immune responses (IL-23), and the Th17 cell pathway (IL-23R, IL-12B, STAT3, JAK2, and TYK2) [38]. Dendritic cells (DCs) followed by CD4 T, natural killer (NK), and NKT cells showed the highest enrichment of these susceptibility gene sets when tested in a panel of immune cell subsets, indicating a major role for these cells in CD pathogenesis [39].

Most of the loci are common for IBD, although some of them are unique for either $\mathrm{CD}$ or UC. NOD-like receptors (NOD2), autophagy genes (ATG16L1, IRGM) and intelectins (ITLN1) present high specificity for CD. Considering UC, gene loci involved in regulatory pathways, such as IL-10 and ARPC2, and in intestinal epithelial cell function, such as ECM1 and E3 ubiquitin ligase, seem to be disease-specific. Furthermore, the association of the human leukocyte antigen/major 
histocompatibility complex region appears to be stronger with UC rather than CD, a genetic feature of IBD shared with several autoimmune diseases [40-42].

GWAS and the meta-analysis of loci have been crucial in the specification of over 230 genetic susceptibility loci linked to IBD [37]; some of these genes are involved in immunity and in barrier function [39]. Various single-nucleotide polymorphisms (SNPs) have been found in genes related to pathogenic cytokine pathways, for example the Th17/IL-23 pathway, IL-10 pathway, and type I IFN signaling [43]. The relevant pathways could not be precisely determined only from the genetic data, as most of the signaling mediators are shared between different cytokine signaling cascades.

Many of the IBD-associated genes are involved in the type I IFN signaling pathway. The rs2284553 SNP is associated with the IFNGR2 gene and with the IFNAR1. SNPs in JAK2, TYK2, STAT1 and STAT3 genes affect the JAK/STAT signaling pathway, deregulating the action of several cytokines, such as IL-22, IL-10, and type I and type III IFN [39]. Moreover, MDA5 or IRF4 gene polymorphisms can modulate the production of type I and type III IFN [39]. Although studies in mice show that minor alterations in type I IFN may contribute to the imbalance of the immune response in the lamina propria, the exact role of type I IFN in IBD pathology remains unclear [44].

\section{IFNs}

IFNs are cytokines that have antiviral activity. They are classified into 3 categories: type I IFNs (IFN- $\alpha$, IFN- $\beta$ and other less explored members), type II IFNs (IFN- $\gamma$ ), and type III IFNs (IFN- $\lambda 1$, IFN- $\lambda 2$, IFN- $\lambda 3$ and IFN- $\lambda 4$ in humans) $[45,46]$.

The type I multigene family consists of structurally related IFNs, such as IFN- $\alpha$, IFN- $\beta$, IFN- $\omega$, IFN- $\varepsilon$, IFN- $\kappa$, IFN- $\delta$, IFN- $\zeta$, and IFN- $\tau$. [45]. The best-studied type I IFN is the IFN- $\alpha$ family, which is encoded by 13 homologous genes [47]. These cytokines are produced after the stimulation of patternrecognition receptors, as part of the innate immune antiviral response [48]. Data indicate that the initial production of IFN- $\beta$ and IFN- $\alpha 4$ is dependent upon IRF3 phosphorylation and NF- $\kappa B$ activation [49]. The primary wave of type I IFN then induces IRF7 phosphorylation, leading to a positive feedback loop to increase the release of type I IFN [50].

Type II IFN (also known as IFN- $\gamma$ ), is predominantly produced by NK and NKT cells, as well as by CD4 and CD8 T-lymphocytes. Along with its antiviral activity, IFN- $\gamma$ also acts against intracellular bacterial infections and tumor progression [51]. There is also evidence to show that type I IFN, IL-12, IL-15 and IL-18 are able to induce production of IFN- $\gamma$ by NK cells [52].

Type III IFNs are more similar in structure to the IL-10 family than to the other IFN subgroups, but functionally they are similar to type I and type II IFN, as they also contribute to antiviral responses and induce the activation of many common genes [53].

All type I IFN members bind to the same heterodimer, expressed on most cells: the type I IFN receptor (IFNAR).
IFNAR is composed of two subunits, IFNAR1 and IFNAR2 [47]. These receptors are endocytosed and activate their related tyrosine kinases, tyrosine kinase 2 (Tyk2) and Janus kinase 1 (JAK1), when bound to IFN type I [54]. The typical signaling cascade results in the phosphorylation of STAT1 and STAT2, which form a complex with IRF9, known as the IFN-stimulated gene factor 3 (ISGF3), leading to the expression of IFN-stimulated genes [54]. Apart from ISGF3, type I IFNs can induce phosphorylation and dimerization of STAT3, STAT4, STAT5 and STAT6 and activate Rap1, CrkL, Map kinases, IRS-1, IRS-2, Vav, RAC1 and PI3-kinase signal transduction pathways [54-59]. IFN- $\beta$ has been shown to act via the IFNAR1, in an IFNAR2-independent way, through a non-canonical pathway [60].

The 2 other categories of the IFN family, type II and type III, display little similarity to type I IFNs and signal through their own cognate receptors. All IFNs act through various signal transduction pathways, with Janus kinases (JAK)/signal transducer and activator of transcription (STAT) pathway being the best-described [61]. Although type II IFN shares a similar classification with type I IFN, it activates different signal receptors that have other effects than those of type I IFN. IFN- $\gamma$ signals through the IFN- $\gamma$ receptor (IFNGR), composed of IFNGR1 and IFNGR2 subunits. In the classical signaling pathway, binding of IFN- $\gamma$ to IFNGR activates JAK1 and JAK2 and leads to homodimerization and phosphorylation of STAT1 at tyrosine 701 [62]. However, like type I IFN, alternative signaling pathways have also been suggested for IFN- $\gamma$, such as STAT4, Erk1/2, Pyk2 and CrkL [63].

Type III IFNs bind to 2 receptors unique to this IFN type that have limited expression in epithelial cells: the low-affinity receptor subunit (IL-10R2) and the high-affinity receptor subunit (IFN- $\lambda$ receptor 1 , IFNLR1) [64]. These receptors trigger the same signaling JAK/STAT pathway as type I IFN receptors and induce a high number of ISGs [65]. All the types of IFNs are summarized in Table 1.

The role of IFNs has been widely studied in autoimmune diseases; however, there are not many data concerning IFNs and IBD. IFNs have multiple direct and indirect effects on adaptive immunity. IFN- $\alpha / \beta$ activates NK cells and DCs, with increased expression of major histocompatibility complex class I (MHCI) and other molecules, such as CD40, CD80 and CD86. Type I IFN affects DC targeting in peripheral lymphoid organs by inducing the production of several chemokines, including CXCL8, CXCL9, CXCL10, CXCL11 and their receptors. It boosts the production of IL-12, IL-15, IL-18 and IL- 23 by DCs and the heightened expression of B-cell activating factor (BAFF) and a proliferation-inducing ligand (APRIL). Furthermore, type I IFN stimulates macrophage development and inducible nitric oxide (NO) synthase expression in systemic lupus erythematosus (SLE) [66]. IFN- $\alpha$ overproduction has been described in SLE patients; immune complexes containing DNA or RNA in the serum of SLE patients may explain this increased production [67]. Immature plasmacytoid DCs produce increased levels of IFN that can also induce monocyte maturation into DCs [68].

The stimulatory or inhibitory role of type I IFN has been described in various other autoimmune disorders. For 
Table 1 The types of interferons

\begin{tabular}{lllll}
\hline IFN Type & Class & Receptor & Cellular source & Biological effect \\
\hline I & $\alpha, \beta, \omega, \varepsilon, \kappa, \delta, \zeta, \tau$ & IFNAR1, IFNAR2 & pDCs, Fibroblasts & $\begin{array}{l}\text { Activates: NK cell, DC, macrophage } \\
\text { development and chemokines production. } \\
\text { Triggers/activates: Rap1, CrkL, Map } \\
\text { kinases, IRS-1, IRS-2, Vav, RAC1 and } \\
\text { PI3- kinase signal transduction pathways }\end{array}$ \\
& & & & $\begin{array}{l}\text { Triggers: JAK/STAT, STAT4, Erk1/2, } \\
\text { II }\end{array}$ \\
& $\gamma$ & IFNGR1, IFNGR2 & $\begin{array}{l}\text { NK cells, CD4 and CD8 cells, } \\
\text { macrophages, DCs, B cells }\end{array}$ & Priggers JAK/STAT pathway, induces ISGs \\
\hline III & $\lambda 1, \lambda 2, \lambda 3, \lambda 4$ & IFNLR1 & pDCs & Trighay
\end{tabular}

IFN, interferon; IFNAR1, interferon $\alpha / \beta$ receptor subunit 1; IFNAR2, interferon $\alpha / \beta$ receptor subunit 2 ; IFNGR1, interferon-gamma receptor subunit 1; IFNGR2, interferon-gamma receptor subunit 2; IFNLR1, Interferon lambda receptor 1; pDCs, plasmacytoid dendritic cells; NK cells, natular killer cells; DC, dendritic cells; ISGs, interferon-stimulated genes

example, type I IFN has been suggested as a negative regulator in rheumatoid arthritis (RA), type I insulin-dependent diabetes mellitus, multiple sclerosis (MS), and acute encephalitis. However, IFN- $\beta$ is used to treat relapsing/remitting forms of MS. Other examples are those of thyroiditis, some forms of autoimmune hemolytic anemia, and Behçet's disease [67].

Genetic studies in primary Sjögren's syndrome (pSS) report polymorphisms in the IRF5 gene, whose transcripts may induce the stimulation of IFN- $\beta$ [69]. A few studies have correlated the increased circulating IFN- $\alpha$ levels with autoimmune/ autoimmune-featured diseases such as pSS, diffuse systemic sclerosis and interstitial lung disease [70]. In dermatomyositis, immunohistochemistry methods revealed that IFN- $\alpha / \beta$ induce the myxovirus resistance protein $\mathrm{A}$ in the perifascicular muscle fibers and in capillary cells [71]. IFN- $\alpha / \beta$ has also been detected in the synovial fluid and tissue of patients with RA. Subsequent treatment approaches using type I IFN have had controversial outcomes in both murine models and humans with RA [72].

It is known that, in healthy individuals, TNF downregulates IFN- $\alpha$ [73], and this leads to an initial theory that the reduction in TNF-mediated IFN- $\alpha$ secretion triggers autoimmunity. However, several studies showed that both IFN- $\alpha$ and TNF are increased in SLE patients and, furthermore, that their levels were indicative of the disease progression [74-78]. It seems that the increased levels of both TNF and IFN- $\alpha$ contribute to the development of autoimmunity [79].

There are studies indicating that type I IFN treatment often has an unpredictable outcome in IBD patients. Some pilot studies have shown that type I IFN may improve the condition of IBD patients $[80,81]$, although some clinical trials found that there is no beneficial outcome of IFN- $\beta 1$, IFN- $\alpha$ or IFN- $\beta 1$ treatment in terms of disease remission [82-84]. According to Mannon et al, UC patients characterized as responders to IFN$\beta 1$ a therapy presented significant lower levels of mucosal T-cell IL-13 production after treatment. Primary non-responders to IFN- $\beta$ la treatment were associated with increased quantities of IL-17 and IL-6, while no other significant decrease in the production of inflammatory cytokines was noticed after clinically and endoscopically effective therapy [85]. We can conclude that, according to the current knowledge concerning type I IFN treatment, no statistical benefit in disease amelioration has been found, although the effect of the treatment seems to be associated with the Th profiles of each patient.
Proinflammatory and anti-inflammatory cytokines, type I IFN included, are significant players in the maintenance of gut microbiota, given their immunoregulatory effects on the growth and renewal of intestinal epithelial cells (IECs) [86-88]. Type I IFN is mainly expressed by lamina propria CD11c+ DCs in the intestine [89]; more specifically, these cells express IFN- $\alpha 5$ and IFN- $\alpha 9$ mRNA, but not IFN- $\alpha 4$ [90]. Moreover, it has been found that CD11c+ DCs express type I IFN-induced genes, including 2'-5' oligoadenylate synthetase (OAS), OAS-like family members, IRF5, IRF7, CXCL10, RNase L and PKR, as well as IL-15a [91].

\section{IFN signature in IBD}

An increased expression of IFN-regulated genes, widely known as an IFN signature, has been reported in blood and tissue from patients with autoimmune disorders. The IFN signature has been studied in multiple autoimmune diseases, such as SLE, subacute cutaneous lupus erythematosus (SCLE), discoid lupus erythematosus (DLE), myositis, pSS, systemic sclerosis (SSc), scleroderma, and RA [92-95].

In SLE, the IFN signature is correlated with disease activity and severity and can be modulated with appropriate therapy [94]. Bauer et al suggest that IFN-induced chemokines can be used as possible biomarkers for predicting SLE [96,97]. The IFN-regulated gene signature is increased in peripheral blood cells and is correlated with disease activity in SCLE and DLE [95]. Furthermore, higher expression levels of IFN- $\lambda 1$ in serum and tissues induce type I IFN-regulated genes in cutaneous lupus erythematosus [98]. The IFN type I signature also defines a subset of RA patients, with a specific biomolecular phenotype, represented by increased activity of the innate defense system, coagulation and complement cascades, and fatty acid metabolism [99]. Similarly, the IFN signature can identify only a subgroup of pSS patients: those who present higher activity of the disease and a more obvious activation of the immune system, including higher BAFF mRNA expression [100]. However, the IFN signature does not have such a strong association with dermatomyositis, polymyositis, SSc and RA, as with SLE [94,101].

Extended research by Smiljanovic et al studied the impact of a large group of cytokines regulated by IFNs and TNF- $\alpha$ in 
SLE and RA. Specifically the IFN- $\alpha 2 \alpha$ signature included the upregulation of the following probe sets: CCL2, CCL8, CD164, CXCL10, CXCL11, FAS, IFI16, IFI27, IFI44, IFI44L, IL-15, IL-15RA, MX1, MX2, OAS1, OAS2, OAS3, OASL, SIGLEC1, SSB, STAT1, STAT2, STAT3 and TNFSF10, and downregulation of the following probe sets: CENTD2, CYP1B1, GPX4, ID2, IER3, IRS2, JUN, KLF13, KLF2, KLF4, PTAFR, TNFAIP2 and TNFRSF10B in SLE. A pronounced IFN- $\alpha 2 \alpha$ signature was also identified in most RA patients. The IFN- $\alpha 2 \alpha$ imprint in RA included the upregulation of CD163, CD55, CITED2, IL6ST, FOSL2, MAFF, ATF3 and MT2A and the downregulation of CCNG2, CXCR4, ICAM2, FADD, GPX3, NGRN, PURA, TNFSF8 and TP53. The network that characterizes an IFN- $\gamma$ signature in SLE contains the following genes: STAT1, STAT3, IFI16, IRF7, CXCL10 and TNFSF10. In contrast, the network that demonstrates an IFN- $\gamma$ imprint in RA contains genes like CCL3, CCL4, CXCR4 and ATF3 [100].

Appendicitis and appendectomy (AA), when occurring at an early age, have been found to be protective against the development of colitis in adulthood [102]. Cheluvappa et al showed that AA influence the expression of IFN-associated genes using microarray and gene set enrichment analysis in an AA model [103], explaining its beneficial role in trinitrobenzenesulfonic acid (TNBS) colitis. In this study, the expression of 46 distal colonic, IFN activity-associated genes was measured 3 and 28 days after AA. At day 3 after AA, IRF7 and IFI35 were significantly upregulated, while IFNK and IFRD2 were significantly downregulated. At day 28 after AA, IFNZ, IFIT1, IFIT2, IFIT3, IRF9, IFIH1 and IFI44 were found significantly upregulated. However, IRF2BP1, IRF2BP2 and IFI30 were significantly downregulated [104]. The only IFN gene that was upregulated at any time point was IFNZ [105]. The $I F N z$ gene in mice exhibits immunomodulatory and antiviral effects, initiated by its IFN- $\alpha / \beta$ receptor binding [105]. These data agree with another study that showed imiquimodinduced colonic upregulation of IFN activity-associated genes or their gene sets (IFIT1, IFIT2, IFIT3, IRF7, IFI44 and IFIH1) that provide protection against DSS colitis [106]. A similar study investigated the role of several chemokines in colitis after AA. At day 28 after AA, CCL5 was significantly upregulated, whereas CCL20 was significantly downregulated. Interestingly,
CXCL11 was found to be significantly upregulated at days 3 and 28 after AA [107]. The IFN-regulated genes in the IBD model, SLE and RA are presented in Table 2.

IFIT1, IFIT2, and IFIT3 are induced by IFNs, virus infections, and several molecular patterns, interfere with multiple protein-protein interactions, and present antiproliferative and immunoregulatory properties [108,109]. The IRF family of transcription factors that bind with DNA has the ability to recognize and bind to consensus gene sequences (IFN, stimulated response elements and virusresponse elements), helping in IFN production, IFN/feedbackinhibition, management of cell growth, T-/B- lymphocyte activity and IFN-induced gene expression [110,111]. Specifically, IRF7 is a positive IFN regulator and a key mediator of the IFN positive feedback amplification loop, while IRF9 contributes toward a heterotrimeric complex, which induces IRF7 via JAK/STAT signaling, and autocrine IFN-receptor activation [110]. IFI44 binds intracellular GTP and prevents cells from proliferating [112], while IFI30 is an enzyme of lysosomal thiol reductase. It is expressed from antigenpresenting cells (APCs) and is responsible for processing the antigen through the decrease of bisulfide bonds of endocytosed proteins [113]. IFI35 is a leucine zipper protein, expressed in fibroblasts, macrophages and epithelial cells [114]. IFIH1 is an RNA helicase involved in induction of translation, in nuclear/ mitochondrial splicing and ribosome assembly [115]. The IFN IFNz in mice exhibits immunoregulatory and antiviral effects, initiated by its IFN- $\alpha / \beta$ receptor binding [105]. Considering the chemokines involved in the IFN signature, the chemokine CCL5 is a chemoattractant for monocytes, memory Th cells, and eosinophils [116], and is induced by IFN- $\gamma$ [117]. The chemokine CCL20 is also induced by IFN- $\gamma$ [117] and is chemoattractant for lymphocytes and neutrophils, which can help lymphoid tissues of mucosa to attract lymphocytes and DCs to epithelial cells [118], while IFN- $\beta$ and IFN $-\gamma$ induce the chemokine CXCL11. CXCL11 is a chemoattractant for ILactivated T-cells [119].

There are not many studies concerning the correlation of the IFN-regulated gene expression and the response to anti-TNF therapy. The aforementioned study of Palucka et al suggests the upregulation of IFN-a regulated genes in circulating leukocytes

Table 2 Interferon (IFN)-regulated genes in the inflammatory bowel disease (IBD) model, Systemic lupus erythematosus (SLE) and Rheumatoid arthritis (RA)

\begin{tabular}{|c|c|c|}
\hline \multirow[t]{2}{*}{ Diseases } & \multicolumn{2}{|l|}{ IFN signature } \\
\hline & Upregulated genes & Downregulated genes \\
\hline $\begin{array}{l}\text { IBD model } \\
\text { (after appendicitis and appendectomy) }\end{array}$ & $\begin{array}{l}\text { IRF7, IFI35, IFNZ, IFIT1, IFIT2, IFIT3, IRF9, IFIH1, IFI44, } \\
\text { IFIT1, IFIT2, IFIT3, IRF7, IFI44, and IFIH1, CCL5, CXCL11 }\end{array}$ & $\begin{array}{l}\text { IFNK, IFRD2, IRF2BP1, } \\
\text { IRF2BP2, IFI30, CCL20 }\end{array}$ \\
\hline SLE & $\begin{array}{l}\text { CCL2, CCL8, CD164, CXCL10, CXCL11, FAS, IFI16, IFI27, } \\
\text { IFI44, IFI44L, IL-15, IL-15RA, MX1, MX2, OAS1, OAS2, OAS3, } \\
\text { OASL, SIGLEC1, SSB, STAT1, STAT2, STAT3, TNFSF10 }\end{array}$ & $\begin{array}{l}\text { CENTD2, CYP1B1, GPX4, } \\
\text { ID2, IER3, IRS2, JUN, KLF13, } \\
\text { KLF2, KLF4, PTAFR, TNFAIP2, } \\
\text { TNFRSF10B }\end{array}$ \\
\hline RA & $\begin{array}{l}\text { CD163, CD55, CITED2, IL6ST, FOSL2, MAFF, ATF3, and } \\
\text { MT2A }\end{array}$ & $\begin{array}{l}\text { CCNG2, CXCR4, ICAM2, FADD, } \\
\text { GPX3, NGRN, PURA, TNFSF8, } \\
\text { TP53 }\end{array}$ \\
\hline
\end{tabular}

IFN, interferon; IBD, inflammatory bowel disease; SLE, systemic lupus erythematosus; RA, rheumatoid arthritis 
of patients with systemic onset juvenile idiopathic arthritis who receive anti-TNF therapy [73]. A study performed in $33 \mathrm{RA}$ patients revealed that increased IFN response gene activity is associated with a poor clinical response to TNF blockade, most evident 2 months after the initiation of treatment. Interestingly, the combination of five IFN response genes (OAS1, LGALS3BP, $M \times 2, O A S 2$ and SERPING1) into one IFN response gene set improved the predictive accuracy compared to OAS1 and LGALS3BP expression separately [120].

Although IBD is not considered as an autoimmune disease, it may trigger autoimmunity caused by the increased antigenic load and mucosal immune activation. It is well established that both innate and adaptive immunity play a major role in IBD development. Several genetic alterations are shared between IBD and autoimmune diseases. Furthermore, chronic intestinal inflammation presented in IBD could trigger autoimmunity. IBD-related inflammation consists of a variety of abnormalities in humoral and cell-mediated immunity, and a generalized enhanced reactivity against intestinal bacteria. The IFN signature in autoimmune diseases represents a useful tool as a biomarker of disease progression and treatment efficiency. Thus, the IFN signature in IBD could serve as an early predictor of disease activity and progression, as well as a supplementary therapeutic target $[121,122]$.

\section{Concluding remarks}

Many autoimmune diseases present an IFN signature in cells from peripheral blood and tissues. Current data demonstrate that the IFN signature can be used as a biomarker that defines disease activity. In RA, the IFN signature may be used in the prediction of treatment response to some biological drugs, while inhibition of the IFN signature in other autoimmune disorders, such as SLE, could have a potential role in clinical practice. The IFN signature in IBD has not been thoroughly studied compared to autoimmune diseases. For this reason, further investigation of the IFN signature in IBD would be essential for a better understanding of its actions.

\section{References}

1. de Souza HSP, Fiocchi C, Iliopoulos D. The IBD interactome: an integrated view of aetiology, pathogenesis and therapy. Nat Rev Gastroenterol Hepatol 2017;14:739-749.

2. Molodecky NA, Soon IS, Rabi DM, et al. Increasing incidence and prevalence of the inflammatory bowel diseases with time, based on systematic review. Gastroenterology 2012;142:46-54.

3. Abraham C, Cho JH. Inflammatory bowel disease. $\mathrm{N}$ Engl J Med 2009;361:2066-2078.

4. Peyrin-Biroulet L, Loftus EV Jr, Colombel JF, Sandborn WJ. The natural history of adult Crohn's disease in population-based cohorts. Am J Gastroenterol 2010;105:289-297.

5. Thomas A, Lodhia N. Advanced therapy for inflammatory bowel disease: a guide for the primary care physician. J Am Board Fam Med 2014;27:411-420.
6. Panitch HS, Folus JS, Johnson KP. Recombinant IFN-b inhibits IFN-gamma production in MS. Ann Neurol 1987;22:137.

7. Brod SA, Marshall GD Jr, Henninger EM, Sriram S, Khan M, Wolinsky JS. Interferon-beta $1 \mathrm{~b}$ treatment decreases tumor necrosis factor-alpha and increases interleukin-6 production in multiple sclerosis. Neurology 1996;46:1633-1638.

8. Rudick RA, Ransohoff RM, Peppler R, VanderBrug Medendorp S, Lehmann P, Alam J. Interferon beta induces interleukin-10 expression: relevance to multiple sclerosis. Ann Neurol 1996; 40:618-627.

9. Schnaper HW, Aune TM, Pierce CW. Suppressor T cell activation by human leukocyte interferon. J Immunol 1983;131:2301-2306.

10. Targan SR, Karp LC. Defects in mucosal immunity leading to ulcerative colitis. Immunol Rev 2005;206:296-305.

11. Hisamatsu T, Suzuki M, Reinecker HC, Nadeau WJ, McCormick BA, Podolsky DK. CARD15/NOD2 functions as an antibacterial factor in human intestinal epithelial cells. Gastroenterology 2003; 124:993-1000.

12. Wehkamp J, Harder J, Weichenthal M, et al. NOD2 (CARD15) mutations in Crohn's disease are associated with diminished mucosal alpha-defensin expression. Gut 2004;53:1658-1664.

13. Wehkamp J, Harder J, Weichenthal $\mathrm{M}$, et al. Inducible and constitutive beta-defensins are differentially expressed in Crohn's disease and ulcerative colitis. Inflamm Bowel Dis 2003;9:215-223.

14. Kugathasan S, Fiocchi C. Progress in basic inflammatory bowel disease research. Semin Pediatr Surg 2007;16:146-153.

15. Cook DN, Pisetsky DS, Schwartz DA. Toll-like receptors in the pathogenesis of human disease. Nat Immunol 2004;5:975-979.

16. Cario E, Podolsky DK. Differential alteration in intestinal epithelial cell expression of toll-like receptor 3 (TLR3) and TLR4 in inflammatory bowel disease. Infect Immun 2000;68:7010-7017.

17. Franchimont D, Vermeire S, El Housni H, et al. Deficient hostbacteria interactions in inflammatory bowel disease? The toll-like receptor (TLR)-4 Asp299gly polymorphism is associated with Crohn's disease and ulcerative colitis. Gut 2004;53:987-992.

18. Török HP, Glas J, Tonenchi L, Bruennler G, Folwaczny M, Folwaczny C. Crohn's disease is associated with a toll-like receptor-9 polymorphism. Gastroenterology 2004;127:365-366.

19. Li J, Moran T, Swanson E, et al. Regulation of IL-8 and IL1beta expression in Crohn's disease associated NOD2/CARD15 mutations. Hum Mol Genet 2004;13:1715-1725.

20. van Heel DA, Ghosh S, Butler M, et al. Muramyl dipeptide and toll-like receptor sensitivity in NOD2-associated Crohn's disease. Lancet 2005;365:1794-1796.

21. Swidsinski A, Ladhoff A, Pernthaler A, et al. Mucosal flora in inflammatory bowel disease. Gastroenterology 2002;122:44-54.

22. D'Haens GR, Geboes K, Peeters M, Baert F, Penninckx F, Rutgeerts P. Early lesions of recurrent Crohn's disease caused by infusion of intestinal contents in excluded ileum. Gastroenterology 1998;114:262-267.

23. Campieri M, Gionchetti P. Probiotics in inflammatory bowel disease: new insight to pathogenesis or a possible therapeutic alternative? Gastroenterology 1999;116:1246-1260.

24. Takahashi F, Das KM. Isolation and characterization of a colonic autoantigen specifically recognized by colon tissue-bound immunoglobulin G from idiopathic ulcerative colitis. J Clin Invest 1985;76:311-318.

25. Podolsky DK, Fiocchi C. Inflammatory Bowel Disease. Cytokines, chemokines, growth factors, eicosanoids and other bioactive molecules in IBD. W.B. Saunders; 1999, pp. 191-207.

26. Janeway CA Jr, Travers P, Walport M, et al. Immunobiology: The Immune System in Health and Disease ( $5^{\text {th }}$ edition). B-cell activation by armed helper $\mathrm{T}$ cells. Garland Science: New York; 2001.

27. Weaver CT, Harrington LE, Mangan PR, Gavrieli M, Murphy KM. Th17: an effector CD4 T cell lineage with regulatory $\mathrm{T}$ cell ties. 
Immunity 2006;24:677-688.

28. Romagnani S. Th1/Th2 cells. Inflamm Bowel Dis 1999;5:285-294.

29. Iwakura $Y$, Ishigame H. The IL-23/IL-17 axis in inflammation. J Clin Invest 2006;116:1218-1222.

30. McGeachy MJ, Cua DJ. The link between IL-23 and Th17 cellmediated immune pathologies. Semin Immunol 2007; 19:372-376.

31. Neurath MF. Cytokines in inflammatory bowel disease. Nat Rev Immunol 2014;14:329-342.

32. Zorzi F, Monteleone I, Sarra M, et al. Distinct profiles of effector cytokines mark the different phases of Crohn's disease. PLoS One 2013;8:e54562.

33. Neurath MF, Weigmann B, Finotto $S$, et al. The transcription factor T-bet regulates mucosal $\mathrm{T}$ cell activation in experimental colitis and Crohn's disease. J Exp Med 2002;195:1129-1143.

34. Monteleone G, Biancone L, Marasco R, et al. Interleukin 12 is expressed and actively released by Crohn's disease intestinal lamina propria mononuclear cells. Gastroenterology 1997;112:1169-1178.

35. Pizarro TT, Michie MH, Bentz $\mathrm{M}$, et al. IL-18, a novel immunoregulatory cytokine, is up-regulated in Crohn's disease: expression and localization in intestinal mucosal cells. J Immunol 1999;162:6829-6835.

36. Fuss IJ, Heller F, Boirivant M, et al. Nonclassical CD1d-restricted NK T cells that produce IL-13 characterize an atypical Th2 response in ulcerative colitis. J Clin Invest 2004;113:1490-1497.

37. Uhlig HH, Muise AM. Clinical Genomics in Inflammatory Bowel Disease. Trends Genet 2017;33:629-641.

38. Franke A, McGovern DP, Barrett JC, et al. Genome-wide metaanalysis increases to 71 the number of confirmed Crohn's disease susceptibility loci. Nat Genet 2010;42:1118-1125.

39. Jostins L, Ripke S, Weersma RK, et al; International IBD Genetics Consortium (IIBDGC). Host-microbe interactions have shaped the genetic architecture of inflammatory bowel disease. Nature 2012;491:119-124.

40. Gregersen PK, Olsson LM. Recent advances in the genetics of autoimmune disease. Annu Rev Immunol 2009;27:363-391.

41. Van Limbergen J, Wilson DC, Satsangi J. The genetics of Crohn's disease. Annu Rev Genomics Hum Genet 2009;10:89-116.

42. Zhernakova A, van Diemen CC, Wijmenga C. Detecting shared pathogenesis from the shared genetics of immune-related diseases. Nat Rev Genet 2009;10:43-55.

43. Liu TC, Stappenbeck TS. Genetics and pathogenesis of inflammatory bowel disease. Annu Rev Pathol 2016;11:127-148.

44. Giles EM, Sanders TJ, McCarthy NE, et al. Regulation of human intestinal T-cell responses by type 1 interferon-STAT1 signaling is disrupted in inflammatory bowel disease. Mucosal Immunol 2017; 10:184-193.

45. Lee AJ, Ashkar AA. The Dual Nature of Type I and Type II Interferons. Front Immunol 2018;9:2061.

46. Prokunina-Olsson L, Muchmore B, Tang W, et al. A variant upstream of IFNL3 (IL28B) creating a new interferon gene IFNL4 is associated with impaired clearance of hepatitis C virus. Nat Genet 2013;45:164-171.

47. Rönnblom L, Eloranta ML. The interferon signature in autoimmune diseases. Curr Opin Rheumatol 2013;25:248-253.

48. Sun L, Wu J, Du F, Chen X, Chen ZJ. Cyclic GMP-AMP synthase is a cytosolic DNA sensor that activates the type I interferon pathway. Science 2013;339:786-791.

49. Honda K, Takaoka A, Taniguchi T. Type I interferon [corrected] gene induction by the interferon regulatory factor family of transcription factors. Immunity 2006;25:349-360.

50. Tamura T, Yanai H, Savitsky D, Taniguchi T. The IRF family transcription factors in immunity and oncogenesis. Annu Rev Immunol 2008;26:535-584.

51. Schroder K, Hertzog PJ, Ravasi T, Hume DA. Interferon-gamma: an overview of signals, mechanisms and functions. J Leukoc Biol
2004;75:163-189

52. Pegram HJ, Andrews DM, Smyth MJ, Darcy PK, Kershaw MH. Activating and inhibitory receptors of natural killer cells. Immunol Cell Biol 2011;89:216-224.

53. Zhou Z, Hamming OJ, Ank N, Paludan SR, Nielsen AL, Hartmann R. Type III interferon (IFN) induces a type I IFN-like response in a restricted subset of cells through signaling pathways involving both the Jak-STAT pathway and the mitogen-activated protein kinases. J Virol 2007;81:7749-7758.

54. Platanias LC. Mechanisms of type-I- and type-II-interferonmediated signalling. Nat Rev Immunol 2005;5:375-386.

55. Uddin S, Lekmine F, Sharma N, et al. The Rac1/p38 mitogenactivated protein kinase pathway is required for interferon alpha-dependent transcriptional activation but not serine phosphorylation of Stat proteins. J Biol Chem 2000;275:2763427640.

56. Uddin S, Yenush L, Sun XJ, Sweet ME, White MF, Platanias LC. Interferon-alpha engages the insulin receptor substrate- 1 to associate with the phosphatidylinositol 3'-kinase. J Biol Chem 1995;270:15938-15941.

57. Uddin S, Majchrzak B, Woodson J, et al. Activation of the p38 mitogen-activated protein kinase by type I interferons. $J$ Biol Chem 1999;274:30127-30131.

58. Platanias LC, Sweet ME. Interferon alpha induces rapid tyrosine phosphorylation of the vav proto-oncogene product in hematopoietic cells. J Biol Chem 1994;269:3143-3146.

59. Ahmad S, Alsayed YM, Druker BJ, Platanias LC. The type I interferon receptor mediates tyrosine phosphorylation of the CrkL adaptor protein. J Biol Chem 1997;272:29991-29994.

60. de Weerd NA, Vivian JP, Nguyen TK, et al. Structural basis of a unique interferon- $\beta$ signaling axis mediated via the receptor IFNAR1. Nat Immunol 2013;14:901-907.

61. O'Shea JJ, Plenge R. JAK and STAT signaling molecules in immunoregulation and immune-mediated disease. Immunity 2012;36:542-550.

62. Shuai K, Schindler C, Prezioso VR, Darnell JE Jr. Activation of transcription by IFN-gamma: tyrosine phosphorylation of a 91kD DNA binding protein. Science 1992;258:1808-1812.

63. Gotthardt D, Sexl V. STATs in NK-Cells: The Good, the Bad, and the Ugly. Front Immunol 2016;7:694.

64. Sommereyns C, Paul S, Staeheli P, Michiels T. IFN-lambda (IFNlambda) is expressed in a tissue-dependent fashion and primarily acts on epithelial cells in vivo. PLoS Pathog 2008;4:e1000017.

65. Bolen CR, Ding S, Robek MD, Kleinstein SH. Dynamic expression profiling of type I and type III interferon-stimulated hepatocytes reveals a stable hierarchy of gene expression. Hepatology 2014;59:1262-1272.

66. Meyer O. Interferons and autoimmune disorders. Joint Bone Spine 2009;76:464-473.

67. Baccala R, Kono DH, Theofilopoulos AN. Interferons as pathogenic effectors in autoimmunity. Immunol Rev 2005; 204:9-26.

68. Blanco P, Palucka AK, Gill M, Pascual V, Banchereau J. Induction of dendritic cell differentiation by IFN-alpha in systemic lupus erythematosus. Science 2001;294:1540-1543.

69. Miceli-Richard C, Comets E, Loiseau P, Puechal X, Hachulla E, Mariette X. Association of an IRF5 gene functional polymorphism with Sjögren's syndrome. Arthritis Rheum 2007;56:3989-3994.

70. Kim D, Peck A, Santer D, et al. Induction of interferon-alpha by scleroderma sera containing autoantibodies to topoisomerase I: association of higher interferon-alpha activity with lung fibrosis. Arthritis Rheum 2008;58:2163-2173.

71. Greenberg SA, Pinkus JL, Pinkus GS, et al. Interferon-alpha/betamediated innate immune mechanisms in dermatomyositis. Ann Neurol 2005;57:664-678.

72. Conigliaro P, Perricone C, Benson RA, et al. The type I IFN 
system in rheumatoid arthritis. Autoimmunity 2010;43:220-225.

73. Palucka AK, Blanck JP, Bennett L, Pascual V, Banchereau J. Crossregulation of TNF and IFN-alpha in autoimmune diseases. Proc Natl Acad Sci U S A 2005;102:3372-3377.

74. Maury CP, Teppo AM. Tumor necrosis factor in the serum of patients with systemic lupus erythematosus. Arthritis Rheum 1989;32:146-150.

75. Studnicka-Benke A, Steiner G, Petera P, Smolen IS. Tumour necrosis factor alpha and its soluble receptors parallel clinical disease and autoimmune activity in systemic lupus erythematosus. Br J Rheumatol 1996;35:1067-1074.

76. Gabay C, Cakir N, Moral F, et al. Circulating levels of tumor necrosis factor soluble receptors in systemic lupus erythematosus are significantly higher than in other rheumatic diseases and correlate with disease activity. J Rheumatol 1997;24:303-308.

77. Aringer M, Stummvoll GH, Steiner G, et al. Serum interleukin-15 is elevated in systemic lupus erythematosus. Rheumatology (Oxford) 2001;40:876-881.

78. Mavragani CP, Niewold TB, Moutsopoulos NM, Pillemer SR, Wahl SM, Crow MK. Augmented interferon-alpha pathway activation in patients with Sjögren's syndrome treated with etanercept. Arthritis Rheum 2007;56:3995-4004.

79. Aringer M, Smolen JS. The role of tumor necrosis factor-alpha in systemic lupus erythematosus. Arthritis Res Ther 2008;10:202.

80. Madsen SM, Schlichting P, Davidsen B, et al. An open-labeled, randomized study comparing systemic interferon-alpha-2A and prednisolone enemas in the treatment of left-sided ulcerative colitis. Am J Gastroenterol 2001;96:1807-1815.

81. Nikolaus S, Rutgeerts P, Fedorak R, et al. Interferon beta-1a in ulcerative colitis: a placebo controlled, randomised, dose escalating study. Gut 2003;52:1286-1290.

82. Pena Rossi C, Hanauer SB, Tomasevic R, Hunter JO, Shafran I, Graffner H. Interferon beta-1a for the maintenance of remission in patients with Crohn's disease: results of a phase II dose-finding study. BMC Gastroenterol 2009;9:22.

83. Tilg $\mathrm{H}$, Vogelsang $\mathrm{H}$, Ludwiczek $\mathrm{O}$, et al. A randomised placebo controlled trial of pegylated interferon alpha in active ulcerative colitis. Gut 2003;52:1728-1733.

84. Pena-Rossi C, Schreiber S, Golubovic G, et al. Clinical trial: a multicentre, randomized, double-blind, placebo-controlled, dose-finding, phase II study of subcutaneous interferon-beta-la in moderately active ulcerative colitis. Aliment Pharmacol Ther 2008;28:758-767.

85. Mannon PJ, Hornung RL, Yang Z, et al. Suppression of inflammation in ulcerative colitis by interferon- $\beta-1 \mathrm{a}$ is accompanied by inhibition of IL-13 production. Gut 2011; 60:449-455.

86. McAleer JP, Kolls JK. Maintaining poise: commensal microbiota calibrate interferon responses. Immunity 2012;37:10-12.

87. Santaolalla R, Abreu MT. Innate immunity in the small intestine. Curr Opin Gastroenterol 2012;28:124-129.

88. Guarner F, Malagelada JR. Gut flora in health and disease. Lancet 2003;361:512-519.

89. Chirdo FG, Millington OR, Beacock-Sharp H, Mowat AM. Immunomodulatory dendritic cells in intestinal lamina propria. Eur J Immunol 2005;35:1831-1840.

90. Kole A, He J, Rivollier A, et al. Type I IFNs regulate effector and regulatory $\mathrm{T}$ cell accumulation and anti-inflammatory cytokine production during T cell-mediated colitis. J Immunol 2013;191:2771-2779.

91. Cho H, Kelsall BL. The role of type I interferons in intestinal infection, homeostasis, and inflammation. Immunol Rev 2014;260:145-167.

92. Bennett L, Palucka AK, Arce E, et al. Interferon and granulopoiesis signatures in systemic lupus erythematosus blood. J Exp Med 2003;197:711-723.
93. Baechler EC, Batliwalla FM, Karypis G, et al. Interferon-inducible gene expression signature in peripheral blood cells of patients with severe lupus. Proc Natl Acad Sci U S A 2003;100:2610-2615.

94. Higgs BW, Liu Z, White B, et al. Patients with systemic lupus erythematosus, myositis, rheumatoid arthritis and scleroderma share activation of a common type I interferon pathway. Ann Rheum Dis 2011;70:2029-2036.

95. Braunstein I, Klein R, Okawa J, Werth VP. The interferonregulated gene signature is elevated in subacute cutaneous lupus erythematosus and discoid lupus erythematosus and correlates with the cutaneous lupus area and severity index score. $\mathrm{Br} \mathrm{J}$ Dermatol 2012;166:971-975.

96. Bauer JW, Petri M, Batliwalla FM, et al. Interferon-regulated chemokines as biomarkers of systemic lupus erythematosus disease activity: a validation study. Arthritis Rheum 2009; 60:3098-3107.

97. Bauer JW, Baechler EC, Petri M, et al. Elevated serum levels of interferon-regulated chemokines are biomarkers for active human systemic lupus erythematosus. PLoS Med 2006;3:e491.

98. Zahn S, Rehkämper C, Kümmerer BM, et al. Evidence for a pathophysiological role of keratinocyte-derived type III interferon (IFN $\lambda$ ) in cutaneous lupus erythematosus. J Invest Dermatol 2011;131:133-140.

99. van der Pouw Kraan TC, Wijbrandts CA, van Baarsen LG, et al. Rheumatoid arthritis subtypes identified by genomic profiling of peripheral blood cells: assignment of a type I interferon signature in a subpopulation of patients. Ann Rheum Dis 2007; 66:1008-1014.

100. Smiljanovic B, Grün JR, Biesen R, et al. The multifaceted balance of TNF- $\alpha$ and type I/II interferon responses in SLE and RA: how monocytes manage the impact of cytokines. J Mol Med (Berl) 2012;90:1295-1309.

101. Reynier F, Petit F, Paye M, et al. Importance of correlation between gene expression levels: application to the type I interferon signature in rheumatoid arthritis. PLoS One 2011;6:e24828.

102. Koutroubakis IE, Vlachonikolis IG, Kouroumalis EA. Role of appendicitis and appendectomy in the pathogenesis of ulcerative colitis: a critical review. Inflamm Bowel Dis 2002;8:277-286.

103. Watson Ng WS, Hampartzoumian T, Lloyd AR, Grimm MC. A murine model of appendicitis and the impact of inflammation on appendiceal lymphocyte constituents. Clin Exp Immunol 2007;150:169-178.

104. Cheluvappa R, Eri R, Luo AS, Grimm MC. Modulation of interferon activity-associated soluble molecules by appendicitis and appendectomy limits colitis-identification of novel anticolitic targets. J Interferon Cytokine Res 2015;35:108-115.

105. Oritani K, Kanakura Y. IFN-zeta/limitin: a member of type I IFN with mild lympho-myelosuppression. J Cell Mol Med 2005; 9:244-254.

106. Sainathan SK, Bishnupuri KS, Aden K, et al. Toll-like receptor-7 ligand Imiquimod induces type I interferon and antimicrobial peptides to ameliorate dextran sodium sulfate-induced acute colitis. Inflamm Bowel Dis 2012;18:955-967.

107. Cheluvappa R, Thomas DG, Selvendran S. The role of specific chemokines in the amelioration of colitis by appendicitis and appendectomy. Biomolecules 2018;8.

108. Guo J, Peters KL, Sen GC. Induction of the human protein P56 by interferon, double-stranded RNA, or virus infection. Virology 2000;267:209-219.

109. Fensterl V, Sen GC. The ISG56/IFIT1 gene family. J Interferon Cytokine Res 2011;31:71-78.

110. Honda K, Taniguchi T. IRFs: master regulators of signalling by Toll-like receptors and cytosolic pattern-recognition receptors. Nat Rev Immunol 2006;6:644-658.

111. Zhao GN, Jiang DS, Li H. Interferon regulatory factors: at the crossroads of immunity, metabolism, and disease. Biochim 
Biophys Acta 2015;1852:365-378.

112. Hallen LC, Burki Y, Ebeling M, et al. Antiproliferative activity of the human IFN-alpha-inducible protein IFI44. J Interferon Cytokine Res 2007;27:675-680.

113. West LC, Cresswell P. Expanding roles for GILT in immunity. Curr Opin Immunol 2013;25:103-108.

114. Bange FC, Vogel U, Flohr T, Kiekenbeck M, Denecke B, Böttger EC. IFP 35 is an interferon-induced leucine zipper protein that undergoes interferon-regulated cellular redistribution. J Biol Chem 1994;269:1091-1098.

115. Moura R, Araujo J, Guimarães R, Crovella S, Brandão L. Interferon induced with helicase $\mathrm{C}$ domain 1 (IFIH1): trends on helicase domain and type 1 diabetes onset. Gene 2013;516:66-68.

116. Stone KD, Prussin C, Metcalfe DD. IgE, mast cells, basophils, and eosinophils. J Allergy Clin Immunol 2010;125:S73-S80.

117. Rauch I, Müller M, Decker T. The regulation of inflammation by interferons and their STATs. JAKSTAT 2013;2:e23820.
118. Cheluvappa R. Experimental appendicitis and appendectomy modulate the CCL20-CCR6 axis to limit inflammatory colitis pathology. Int J Colorectal Dis 2014;29:1181-1188.

119. Müller M, Carter S, Hofer MJ, Campbell IL. Review: The chemokine receptor CXCR3 and its ligands CXCL9, CXCL10 and CXCL11 in neuroimmunity-a tale of conflict and conundrum. Neuropathol Appl Neurobiol 2010;36:368-387.

120. van Baarsen LG, Wijbrandts CA, Rustenburg F, et al. Regulation of IFN response gene activity during infliximab treatment in rheumatoid arthritis is associated with clinical response to treatment. Arthritis Res Ther 2010;12:R11.

121. Bar Yehuda S, Axlerod R, Toker O, et al. The association of inflammatory bowel diseases with autoimmune disorders: a report from the epi-IIRN. J Crohns Colitis 2019;13:324-329.

122. Geremia A, Biancheri P, Allan P, Corazza GR, Di Sabatino A. Innate and adaptive immunity in inflammatory bowel disease. Autoimmun Rev 2014;13:3-10. 